\title{
Syndrome of Ventricular Septal Defect and Aortic Regurgitation - A 22-Year Review of its Management
}

Sivakumar Krishnasamy', FRCS, CTh; Sivakumar Sivalingam², FRCS, CTh; Jeswant Dillon², FRCS; Raja Amin Raja Mokhtar ${ }^{1}$, FRCS; A. Yakub², FRCS; Ramesh Singh ${ }^{3}$, MRCP

DOI: $10.21470 / 1678-9741-2020-0207$

\begin{abstract}
Introduction: The presence of aortic regurgitation (AR) in the setting of ventricular septal defect (VSD) has always been a management challenge.

Methods: This is a retrospective study looking at patients who underwent VSD closure with or without aortic valve intervention between January 1st, 1992 and December 31st, 2014 at the Institute Jantung Negara. This study looked at all cases of VSD and $A R$, where AR was classified as mild, moderate, and severe, the intervention done in each of this grade, and the durability of that intervention. The interventions were classified as no intervention (NI), aortic valve repair (AVr), and aortic valve replacement (AVR).

Results: A total of $\mathbf{2 6 1}$ patients were recruited into this study. Based on the various grades of AR, 105 patients had intervention
\end{abstract}

to their aortic valve during VSD closure. The rest 156 had NI. All patients were followed up for a mean time of $13.9 \pm 3.5$ years. Overall freedom from reoperation at 15 years was $82.6 \%$ for AVr. Various factors were investigated to decide on intervening on the aortic valve during VSD closure. Among those that were statistically significant were the grade of AR, size of VSD, age at intervention, and number of cusp prolapse.

Conclusion: We can conclude from our study that all moderate and severe AR with small VSD in older patients with more than one cusp prolapse will need intervention to their aortic valve during the closure of VSD.

Keywords: Aortic Valve Insufficiency. Reoperation. Heart Septal Defects, Ventricular. Heart Valve Prosthesis. Cardiac Surgical Procedures. Prolapse.

\section{Abbreviations, acronyms \& symbols}

$\begin{array}{ll}\mathrm{AR} & =\text { Aortic regurgitation } \\ \mathrm{AVr} & =\text { Aortic valve repair } \\ \mathrm{AVR} & =\text { Aortic valve replacement } \\ \mathrm{CI} & =\text { Confidence interval } \\ \mathrm{DCSA} & =\text { Doubly committed subaortic }\end{array}$

\section{INTRODUCTION}

Combination of ventricular septal defect (VSD) and aortic regurgitation (AR) due to prolapse of right coronary or, less frequently, non-coronary cusp is known as Laubry-Pezzi syndrome ${ }^{[1]}$. Early VSD closure have been proposed to prevent the onset of $A R$ or the worsening of the existing $A R$.

However, once an aortic valve deformity is present, surgical closure of VSD alone without intervention to the aortic valve

$\begin{array}{ll}\text { HR } & =\text { Hazard ratio } \\ \text { IJN } & =\text { Institute Jantung Negara } \\ \text { NI } & =\text { No intervention } \\ \text { PM } & =\text { Perimembranous } \\ \text { VSD } & =\text { Ventricular septal defect }\end{array}$

'Department of Surgery, Cardiothoracic Surgery, University Malaya, Kuala Lumpur, Malaysia.

2Department of Cardiothoracic Surgery, National Heart Institute, Kuala Lumpur, Malaysia.

${ }^{3}$ Department of Medicine, Cardiology Division, University Malaya, Kuala Lumpur, Malaysia.

This study was carried out at the Department of Surgery, Cardiothoracic Surgery, University Malaya, Kuala Lumpur, Malaysia. may not be enough to prevent progressive AR. These patients will require aortic valve repair $(A V r)$ or aortic valve replacement (AVR). Aortic valve prolapse and AR are more frequent and severe in patients with delayed surgery, highlighting the importance of early surgical intervention.

In patients with VSD and concomitant AR, moderate and severe $A R$ represent a challenging surgical issue. AVR is often associated with major drawbacks.
Correspondence Address: Sivakumar Krishnasamy

(iD) https://orcid.org/0000-0002-2996-1775

Cardiothoracic Division, Department of Surgery, Faculty of Medicine, University

Malaya, Jalan University

Kuala Lumpur, Malaysia - Zip Code: 50603

E-mail: sivaprotoss77@yahoo.com 
Mechanical prosthetics require long-term anticoagulation therapy and are often limited by the size of the aortic annulus. On the other hand, homografts and bioprosthetic valves have a high rate of early calcification and failure. Therefore, AVr has been an attractive alternative in the treatment of AR instead of AVR. Hence, this study is aimed mainly at looking at the longterm outcome of aortic valve intervention done in patients with syndrome of VSD and AR.

\section{Objectives}

\section{Primary Objective}

To assess the outcome of aortic valve intervention in patients with AR in the setting of VSD.

\section{Secondary Objective}

To identify variables that may predict the outcome of AVr and the risk of reoperation in our study population.

\section{METHODS}

This is a retrospective study. Patients with VSD and concomitant AR who underwent VSD repair with or without aortic valve intervention between January $1^{\text {st }}, 1992$ and December 31 31 st 2014 at the Institute Jantung Negara (IJN), Kuala Lumpur (Malaysia), were included in this study. The patients were classified into two major groups where in one group the severity of AR was classified as mild, moderate, and severe, and in the other group the type of aortic valve intervention was classified as no intervention (NI), AVr, and AVR. Correlations between the severity of $A R$ and the type of intervention used to address the $A R$ were all analyzed, and the outcomes of each of these were reviewed together with the factors that contributed to them.

\section{Sample Selection}

\section{Inclusion Criteria}

All patients with VSD and concomitant AR who underwent VSD closure with or without intervention to the aortic valve.

\section{Exclusion Criteria}

- Patients with other major cardiac anomalies.

- Patients with congenital syndromes.

- Patients with other comorbidities who are unfit for VSD closure.

- Patients with connective tissue disease or aortopathy features.

\section{Data Collection}

The operation theatre logbooks were reviewed from January $1^{\text {st }}, 1992$ up to December 31 1 st, 2014 . Ethics approval to review all the patients' medical records were obtained for the Ethics Committee of IJN, Kuala Lumpur, in 2012. All patients who underwent VSD closure were identified and their medical records were reviewed. Only those who had concomitant AR were included in this study.

Patients were divided into three groups - mild $A R$, moderate $A R$, and severe $A R$ - based on their preoperative echocardiographic findings. Further information regarding aortic valve intervention for AR was obtained from the operative notes. They were further subdivided into three groups based on the intervention performed - AVr, AVR, and NI.

Postoperative echocardiographic results were reviewed from patients' case notes to assess improvement in the grade of AR after intervention (prior to discharge). All the echocardiographic assessment was done transthoracically as, until 1999, we did not have the small probe for transesophageal echocardiography and hence, in order to standardize our findings, we used the transthoracic data to assess all patients. We also noted that there was not much discrepancy of findings among the patients comparing who had transesophageal and who had transthoracic echocardiography after 1999. On follow-up, patients' AR were quantified based on echocardiographic findings from the medical records. The AR gradient was quantified using pressure half-time measurement. Single measurement was taken for all the VSD. The size was taken as the intraoperative measurement size stated in the operative logbook by the surgeon.

Echocardiographic size of the VSD was not taken as with the presence of a prolapsed leaflet, the size measured might not be accurate. Other details about type of VSD, number of prolapsed cusps, type of $\mathrm{AVr}$, cardiopulmonary bypass time, cross-clamp time, postoperative complications, and the need for reoperation were obtained from the operative notes and medical records. We define failure of the intervention if $A R$ is more than moderate on pressure half-time measurement. We also tested all the valves with saline leak test intraoperatively and we accept success of the intervention if the three aortic cusps come together and hold the saline with not much leak into the ventricle.

\section{Statistical Analysis}

All data were entered and analyzed using IBM Corp. Released 2011, IBM SPSS Statistics for Windows, Version 20.0, Armonk, NY: IBM Corp. Statistical significance was set at a $P$-value of $<0.05$.

Preoperative AR grades were divided into three categories: mild, moderate, and severe AR. These categorical variables were compared with other variables using Pearson's chi-squared test.

Differences in parametric variables among those three groups were compared by one-way analysis of variance (or ANOVA).

Univariate regression analysis was used to determine factors affecting the outcome of AVr. Multivariate analysis was then performed if there was presence of a predictive factor. Freedom from reoperation was analyzed by using Kaplan-Meier actuarial survival analysis. The log rank test was used for comparisons of Kaplan-Meier freedom from reoperation curves.

\section{RESULTS}

\section{Patient Population}

A total of 261 patients who met the inclusion criteria between January 1992 and December 2014 were included in the study. The mean age at surgery was $10.6 \pm 9.3$ years, with $60.9 \%$ of the patients being male. There were 170 (65\%) Malay patients, 56 (21.5\%) Chinese patients, 12 (4.6\%) Indian patients, and 23 (8.8\%) other origin patients. 
Most of our patients (50.6\%) had perimembranous VSD, followed by doubly committed subaortic VSD (46\%), and muscular VSD (3.4\%). The mean VSD size was $1.2 \pm 0.6 \mathrm{~cm}$ (range: $0.4-3.0 \mathrm{~cm}$ ). Among these 261 patients with AR in the setting of VSD, 164 (62.8\%) had mild AR, 54 (20.7\%) had moderate AR, and 43 (16.5\%) had severe AR.

Further cross tabulation (Pearson's chi-squared test) revealed that there was significant association between VSD size and preoperative AR grade in this study $(P=0.002)$. The preoperative $A R$ grade was also significantly associated with the patients' age $(P=0.022)$ (Figure 1). Moreover, it was also found that there was a significant association between the number of prolapsed cusps and grade of AR preoperatively $(P<0.001)$. Those patients with two or three prolapsed cusps had higher incidence of moderate and severe AR as compared to those with none or one prolapsed cusp, who had mainly mild AR (Figure 2).

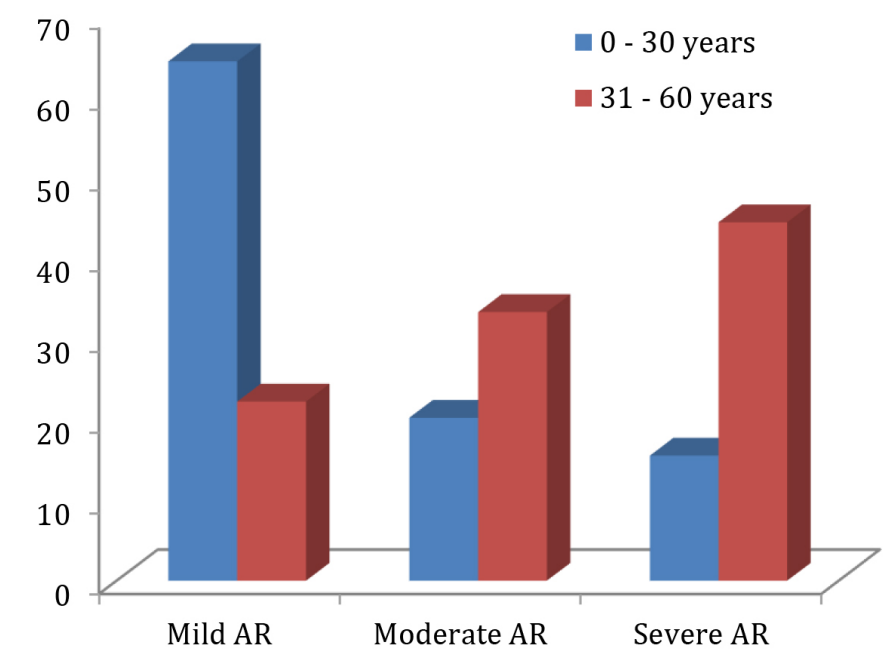

Fig. 1 - Grade of aortic regurgitation $(A R)$ based on age group $(P=0.022)$.

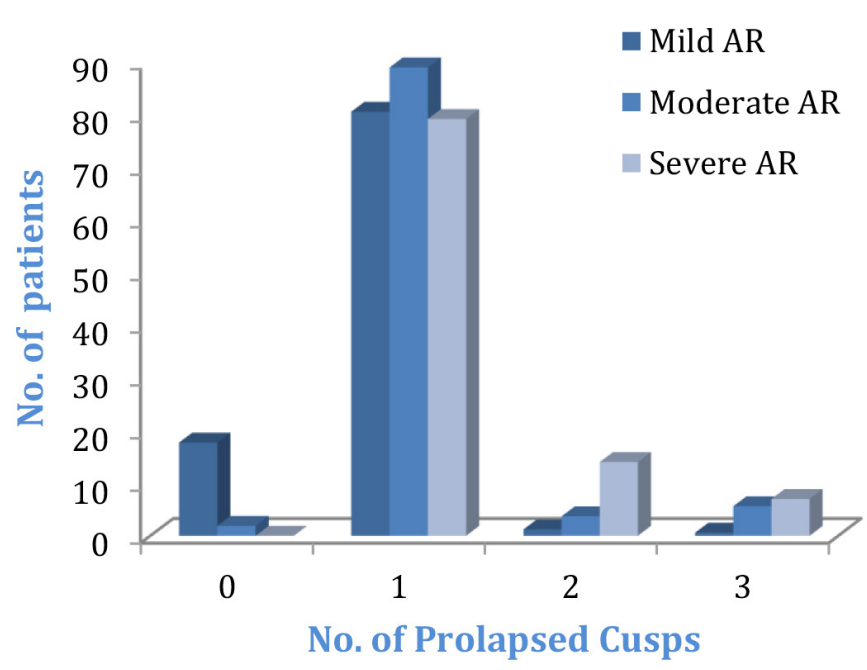

Fig. 2 - Number of prolapsed cusps and grade of aortic regurgitation (AR) $(P<0.001)$.

\section{Operative Results}

Aortic valve intervention for various grades of $A R$ is shown in Table 1. AVr was performed in 84 patients (32.1\%), AVR in 21 (8\%), while the remaining 156 patients (59.8\%) had NI performed for the aortic valve. Most of the patients with mild AR had NI done (90.9\%), while the majority of those with moderate AR had AVr, which was 38 patients (77.8\%). The other five (10\%) patients had AVR, and six (12.8\%) patients had $\mathrm{NI}$ in the moderate AR group. Forty-three patients had severe AR, 27 (62.8\%) of them had AVr and 16 (37.2\%) had AVR. In the mild AR group, 9.1\% of the patients had valve repair, and all these patients underwent repair as the right coronary cusp was prolapsed into the VSD defect, and because of this excess tissue in the defect the aorta was also opened and the aortic valves were examined. The decision to repair was made by the operating surgeon and out of the 15 mild AR cases that were repaired, 12 had Trussler's Repair and three had leaflet plication. On the contrary, there was $12.2 \%$ of moderate AR that was not intervened as the operating surgeon felt that there was adequate leaflet coaptation and there was no leaflet pathology to be addressed.

In this study, 84 patients underwent $A V r$, where 50 out of the 84 (59.5\%) patients had Trussler's repair, followed by commissural-

Table 1. Aortic valve intervention for the study population $(\mathrm{N}=261)$.

\begin{tabular}{|c|c|c|c|c|c|}
\hline & & \multicolumn{3}{|c|}{ Intervention } & \multirow[b]{2}{*}{ Total } \\
\hline & & $\mathrm{AVr}$ & AVR & $\mathrm{NI}$ & \\
\hline \multirow[t]{3}{*}{ Grade of AR } & Mild & 15 (9.1\%) & $0(0 \%)$ & 149 (90.9\%) & $164(100 \%$ \\
\hline & Moderate & $42(77.8 \%)$ & $5(9.2 \%)$ & $7(13.0 \%)$ & 54 (100\%) \\
\hline & Severe & 27 (62.8\%) & $16(37.2 \%)$ & $0(0 \%)$ & 43 (100\%) \\
\hline Total & & 84 & 21 & 156 & 261 \\
\hline
\end{tabular}

$A R=$ aortic regurgitation; $A V r=$ aortic valve repair; $A V R=$ aortic valve replacement; $\mathrm{NI}=$ no intervention 
related repair (15.5\%), leaflet plication (13.1\%), and others (11.9\%). It was shown that there is a significant association between the type of repair performed and the number of prolapsed cusps in this study $(P=0.002)$. Various factors were associated with the decision on the type of aortic valve intervention, especially when dealing with moderate and severe AR. It was shown in this study (Table 2), that the following factors had significant association with the type of aortic valve intervention (AVr/AVR/ $\mathrm{NI})$ : age $(P<0.001)$, size of VSD $(P<0.001)$, grade of preoperative $A R$ $(P<0.001)$, and number of prolapsed cusps $(P<0.001)$.

In terms of age, those of the older age group ( $\geq 31$ years) had a higher percentage of AVR (55.6\%), while those in the younger age group ( $\leq 30$ years) had a higher percentage of $\mathrm{NI}(61.1 \%)$ and $\mathrm{AVr}$ (32.5\%) $(P<0.001)$. In this study, it was also noted that the type of aortic valve intervention (AVr/AVR/NI) was significantly affected by the number of prolapsed cusps ( $P<0.001)$. Most of patients with three prolapsed cusps had AVR (71.4\%) done, while patients with none or one prolapsed cusp had $\mathrm{NI}$ done (100\% and 58.9\%, respectively).

In the immediate postoperative period, there was one failure of repair in the mild AR group and another failure in the moderate AR group, but no failure in the severe AR group (Table 3). There was also one failure in the mild AR group who did not have any intervention. During the follow-up period (Table 4), in the mild AR group, there were two failures in the AVr group and six failures in the NI group. The moderate AR group had seven failures in the $A V r$ group, and the severe AR group had five failures in the AVr group. There were no failures in the immediate and follow-up periods for the patients who underwent AVR.

Univariate analysis was performed to determine the factors influencing the outcome of AVr on follow-up to improve patient selection in the future. Factors such as age, type of VSD, VSD size, preoperative grade of $\mathrm{AR}$, cross-clamp time, cardiopulmonary bypass time, type of $A V r$, and $A R$ grade immediately after operation, as well as the number of prolapsed cusps, were analyzed (Table 5). Age and type of AVr significantly affected the outcome of $\operatorname{AVr}(P<0.05)$. We found that younger patients and those who underwent leaflet plication as their repair technique had better outcome compared to others.

Using similar factors, univariate analysis was also performed to determine the factors affecting reoperation (Table 6). It was noted that, in this study, the VSD size as well as the postoperative AR grade significantly affected reoperation ( $P$-values of 0.048 and $<0.001$, respectively).

A residual moderate or severe ARin the immediate postoperative period has been shown to be the main reason for reoperation in our cohort of patients. Pertaining to VSD size, we also found that the patients with smaller size VSD had higher incidence for reoperation.

There was no hospital mortality among these 261 patients. Overall freedom from reoperation at 10 and 15 years were $86.9 \%$ and $85.6 \%$, respectively, for $A V r$, and freedom from reoperation for AVR at 10 and 15 years were $88.9 \%$ and $88.9 \%$, respectively.

Among those with $\mathrm{NI}$, freedom from reoperation at 10 and 15 years were $98.0 \%$ for both periods. The Kaplan-Meier curve in Figure 3 shows that there are no significant differences in the freedom from reoperation among all three groups (log rank, $P$-value of 0.074$)$. Figure 4 depicts the freedom from reoperation for various methods of AVr. There is no significant difference in the freedom from reoperation among all four repair groups ( $P$-value of 0.673). For those who underwent leaflet plication as a method of $\mathrm{AVr}$, freedom from reoperation at 10 and 15 years were 100\% in this study. For Trussler's repair, the freedom from reoperation was $83.8 \%$ at 10 years as well as 15 years, while for commissural-related procedures, the freedom from reoperation at 10 and 15 years were $84 \%$ and $83.3 \%$, respectively.

All patients were followed up for a mean time of $13.9 \pm 3.5$ years (range: $0.5-25$ years). Among the 261 patients who were included in this study, 114 (43.7\%) of them are still under followup, 73 (28\%) have been discharged from follow-up, while 52 patients (19.9\%) have been transferred to another state hospital for follow-up and 22 (8.4\%) patients are lost to follow-up.

The patients with moderate and severe AR had longer followup (mean time of $15.6 \pm 4.6$ years and $15.4 \pm 4.2$ years, respectively). The follow-up duration was shorter in the mild AR group (mean time of $2.9 \pm 2.3$ years).

\section{DISCUSSION}

This study demonstrates that patients with VSD and concomitant AR have several treatment options. Addressing the aortic valve at an earlier age has been shown to provide a better outcome $^{[1]}$.

This is due to the fact that, if left untreated, AR will progress to a more severe form in the older age, necessitating AVR rather than $A V_{r}[2,3]$.

In most patients, AR tends to be detected between the ages of three to eight years ${ }^{[4]}$. This is consistent in our study, in which the median age at operation was eight years. Older patients presented with more severe AR ( $P=0.022)$. The median age for the AVR group was older (25 years old) while those who underwent $A V r$ were younger (median age of nine years).

Previous reports ${ }^{[2,3]}$ have pointed out that the grade of $A R$ is associated with the size of VSD, and this relationship was also seen in this study ( $P$-value of 0.002). A large VSD has been shown to have a lower AR gradient. The reason for this has been mainly related to the venturi effect that happens to the leaflets. In a smaller VSD defect, the suction effect to the leaflet is far greater than in a larger defect, and this displace the cusp even more and exaggerates the prolapse of the leaflets, hence worsening the $A R^{[2]}$. We had 15 patients with VSD size of $>2.1 \mathrm{~cm} ; 40 \%$ of these patients had mild AR, 33\% had moderate AR, while only $27 \%$ had severe AR. This showed that the larger the VSD size, the lesser the severity of AR. In a small VSD, the venturi effect is far greater than in larger VSDs. This also will exert more strain to the affected leaflet.

Constant pulling effect on the affected leaflet can damage the microarchitecture of the leaflet and this can predispose the leaflet to fail in coming years.

Echocardiography is not very reliable in providing the true size of the VSD, especially in the presence of AR, because the true size tends to be underestimated ${ }^{[5]}$. The best method would still be intraoperative measurement of the VSD defect, which was performed in this study.

Although the syndrome of VSD and AR has been long recognized as a clinical entity, there is still no common agreement about its management, particularly with regards to the indication, 
Table 2. Patients' characteristics for various types of aortic valve intervention.

\begin{tabular}{|c|c|c|c|c|c|}
\hline & $\mathrm{AVr}$ & AVR & $\mathrm{NI}$ & Total & $P$-value \\
\hline \multicolumn{6}{|l|}{ Age (years) } \\
\hline Range & $1-53$ & $9-59$ & $0.3-51$ & & 0.001 \\
\hline Median & 9 & 25 & 7 & & \\
\hline \multicolumn{6}{|l|}{ Race } \\
\hline Malay & $52(30.6 \%)$ & 10 (5.9\%) & 108 (63.5\%) & 170 & 0.265 \\
\hline Indian & $4(33.3 \%)$ & $3(25 \%)$ & $5(41.7 \%)$ & 12 & \\
\hline Chinese & 20 (35.7\%) & $6(10.7 \%)$ & 30 (53.6\%) & 56 & \\
\hline Others & $8(34.8 \%)$ & $2(8.7 \%)$ & $13(56.5 \%)$ & 23 & \\
\hline \multicolumn{6}{|l|}{ Sex } \\
\hline Male & $57(35.8 \%)$ & $12(7.5 \%)$ & $90(56.7 \%)$ & 159 & 0.286 \\
\hline Female & $27(26.5 \%)$ & 9 (8.8\%) & $66(64.7 \%)$ & 102 & \\
\hline \multicolumn{6}{|l|}{ Type of VSD } \\
\hline PM VSD & $41(31 \%)$ & $10(7.6 \%)$ & $81(61.4 \%)$ & 132 & 0.903 \\
\hline DCSA VSD & $39(32.5 \%)$ & $10(8.3 \%)$ & $71(59.2 \%)$ & 120 & \\
\hline Muscular VSD & $4(44.4 \%)$ & $1(11.2)$ & $4(44.4 \%)$ & 9 & \\
\hline \multicolumn{6}{|l|}{ Size of VSD $(\mathrm{cm})$} \\
\hline Mean & 1.395 & 1.495 & 1.090 & & 0.001 \\
\hline \multicolumn{6}{|l|}{ Degree of AR } \\
\hline Mild AR & $15(9.1 \%)$ & $0(0 \%)$ & 149 (90.9\%) & 164 & 0.001 \\
\hline Moderate AR & $42(77.8 \%)$ & $5(9.3 \%)$ & $7(13 \%)$ & 54 & \\
\hline Severe AR & 27 (62.8\%) & $16(37.2 \%)$ & $0(0 \%)$ & 43 & \\
\hline
\end{tabular}

Number of prolapsed cusps

\begin{tabular}{c|c|c|c|c|c}
\hline 0 & $0(0 \%)$ & $0(0 \%)$ & $30(100 \%)$ & 30 & 0.001 \\
\hline 1 & $75(35 \%)$ & $13(6.1 \%)$ & $126(58.9 \%)$ & 214 & \\
\hline 2 & $7(70 \%)$ & $3(30 \%)$ & $0(0 \%)$ & 10 & 7 \\
\hline 3 & $2(28.6 \%)$ & $5(71.4 \%)$ & $0(0 \%)$ & & \\
\hline
\end{tabular}

Immediate postoperative period

\begin{tabular}{l|c|c|c|c|c}
\hline Success & $82(97.6 \%)$ & $21(100 \%)$ & $155(99.4 \%)$ & 258 & 0.423 \\
\hline Failure & $2(2.4 \%)$ & $0(0 \%)$ & $1(0.6 \%)$ & 3 & \\
\hline Follow-up
\end{tabular}

\begin{tabular}{l|c|c|c|c|c}
\hline Success & $63(81.8 \%)$ & $21(100 \%)$ & $142(95.9 \%)$ & 226 & 0.017 \\
\hline Failure & $14(18.2 \%)$ & $0(0 \%)$ & $6(4.1 \%)$ & 20 & 15 \\
\hline Missing data & $7(46.7 \%)$ & $0(0 \%)$ & $8(53.3 \%)$ & \\
\hline
\end{tabular}

\section{Mode of follow-up}

\begin{tabular}{l|c|c|c|c|c}
\hline Lost to follow-up & $15(68.2 \%)$ & $1(4.5 \%)$ & $6(27.3 \%)$ & 22 & 0.001 \\
\hline Discharged & $28(38.4 \%)$ & $9(12.3 \%)$ & $36(49.3 \%)$ & 73 & 114 \\
\hline Still on follow-up & $27(23.7 \%)$ & $8(7.0 \%)$ & $79(69.3 \%)$ & 52 & \\
\hline Transferred out & $14(26.9 \%)$ & $3(5.8 \%)$ & $35(67.3 \%)$ & \\
\hline
\end{tabular}

$\mathrm{AR}=$ aortic regurgitation; $\mathrm{AV} r=$ aortic valve repair; $\mathrm{AVR}=$ aortic valve replacement; $\mathrm{DCSA}=$ doubly committed subaortic; $\mathrm{NI}=\mathrm{no}$ intervention; $\mathrm{PM}=$ perimembranous; $\mathrm{VSD}=$ ventricular septal defect 
Table 3. Success of aortic valve intervention immediately after operation.

\begin{tabular}{|c|c|c|c|c|}
\hline \multirow{2}{*}{ AR Grade } & & \multicolumn{2}{|c|}{ Postoperative success } & \multirow{2}{*}{ Total } \\
\hline & & Success & Failure & \\
\hline \multirow{3}{*}{ Mild AR } & $A V r$ & 14 (93.3\%) & $1(6.7 \%)$ & 15 (100\%) \\
\hline & AVR & - & - & - \\
\hline & $\mathrm{NI}$ & $148(99.3 \%)$ & $1(0.7 \%)$ & $149(100 \%$ \\
\hline \multirow{3}{*}{ Moderate AR } & $A V r$ & $41(97.6 \%)$ & $1(2.4 \%)$ & 42 (100\%) \\
\hline & AVR & $5(100 \%)$ & $0(0 \%)$ & $5(100 \%)$ \\
\hline & $\mathrm{NI}$ & 7 (100\%) & $0(0 \%)$ & 7 (100\%) \\
\hline \multirow{3}{*}{ Severe AR } & $A V r$ & 27 (100\%) & $0(0 \%)$ & 27 (100\%) \\
\hline & AVR & $16(100 \%)$ & $0(0 \%)$ & $16(100 \%)$ \\
\hline & $\mathrm{NI}$ & - & - & - \\
\hline
\end{tabular}

$\mathrm{AR}=$ aortic regurgitation; $\mathrm{AV} r=$ aortic valve repair; $\mathrm{AVR}=$ aortic valve replacement; $\mathrm{NI}=$ no intervention

Table 4. Success of aortic valve intervention during follow-up.

\begin{tabular}{|c|c|c|c|c|}
\hline \multirow{2}{*}{ AR Grade } & & \multicolumn{2}{|c|}{ Success on follow-up } & \multirow{2}{*}{ Total } \\
\hline & & Success & Failure & \\
\hline \multirow{3}{*}{ Mild AR } & $\mathrm{AVr}$ & $11(84.6 \%)$ & $2(15.4 \%)$ & $13(100 \%)$ \\
\hline & AVR & - & - & - \\
\hline & $\mathrm{NI}$ & $136(95.8 \%)$ & $6(4.2 \%)$ & $142(100 \%)$ \\
\hline \multirow{3}{*}{ Moderate AR } & $A V r$ & $31(81.6 \%)$ & $7(18.4 \%)$ & $38(100 \%)$ \\
\hline & AVR & $5(100 \%)$ & $0(0 \%)$ & $5(100 \%)$ \\
\hline & $\mathrm{NI}$ & $6(100 \%)$ & $0(0 \%)$ & $6(100 \%)$ \\
\hline \multirow{3}{*}{ Severe AR } & $A V r$ & 21 (80.8\%) & $5(19.2 \%)$ & $26(100 \%)$ \\
\hline & AVR & $16(100 \%)$ & $0(0 \%)$ & $16(100 \%)$ \\
\hline & $\mathrm{NI}$ & - & - & - \\
\hline
\end{tabular}

$A R=$ aortic regurgitation; $A V r=$ aortic valve repair; $A V R=$ aortic valve replacement; $\mathrm{NI}=$ no intervention

Table 5. Univariate analysis (Cox regression) for predictors of success of aortic valve repair on follow-up.

\begin{tabular}{|c|c|c|c|}
\hline & Beta coefficient & $\mathrm{HR}(95 \% \mathrm{Cl})$ & $P$-value \\
\hline Age & 0.039 & $1.040(1.006-1.074)$ & 0.020 \\
\hline Type of VSD & -0.066 & $0.936(0.789-1.111)$ & 0.451 \\
\hline VSD size & 0.065 & $1.067(0.699-1.627)$ & 0.764 \\
\hline Preoperative AR grade & -0.135 & $0.873(0.583-1.329)$ & 0.512 \\
\hline Cross-clamp time & 0.001 & $1.001(0.991-1.010)$ & 0.899 \\
\hline Bypass time & -0.004 & $0.996(0.988-1.005)$ & 0.396 \\
\hline Type of $A V r$ & 0.523 & $1.687(1.054-2.699)$ & 0.029 \\
\hline Postoperative AR grade & 0.175 & $1.191(0.846-1.678)$ & 0.317 \\
\hline No. of prolapsed cusps & -0.213 & $0.808(0.105-6.245)$ & 0.838 \\
\hline
\end{tabular}

$A R=$ aortic regurgitation; $A V r=$ aortic valve repair; $C l=$ confidence interval; $H R=$ hazard ratio; $V S D=$ ventricular septal defect 
Table 6. Univariate analysis (Cox regression) for predictors of reoperation in the aortic valve repair group.

\begin{tabular}{l|c|c|c}
\hline & Beta coefficient & HR (95\% Cl) & P-value \\
\hline Age & 0.027 & $1.028(0.956-1.105)$ & 0.458 \\
\hline Type of VSD & 0.064 & $1.066(0.652-1.743)$ & 0.798 \\
\hline VSD size & 1.032 & $2.807(1.008-7.815)$ & 0.048 \\
\hline Preoperative AR grade & 0.532 & $1.703(0.569-5.094)$ & 0.341 \\
\hline Cross-clamp time & -0.009 & $1.001(0.991-1.010)$ & 0.565 \\
\hline Bypass time & -0.006 & $0.992(0.963-1.021)$ & 0.624 \\
\hline Type of AVr & -0.285 & $0.752(0.340-1.664)$ & 0.482 \\
\hline Postoperative AR grade & 3.039 & $20.89(4.828-90.354)$ & $<0.001$ \\
\hline No. of prolapsed cusps & 0.341 & $1.406(0.415-4.756)$ & 0.584 \\
\hline
\end{tabular}

$\mathrm{AR}=$ aortic regurgitation; $\mathrm{AV} \mathrm{r}=$ aortic valve repair; $\mathrm{Cl}=$ confidence interval; $\mathrm{HR}=$ hazard ratio; $\mathrm{VSD}=$ ventricular septal defect

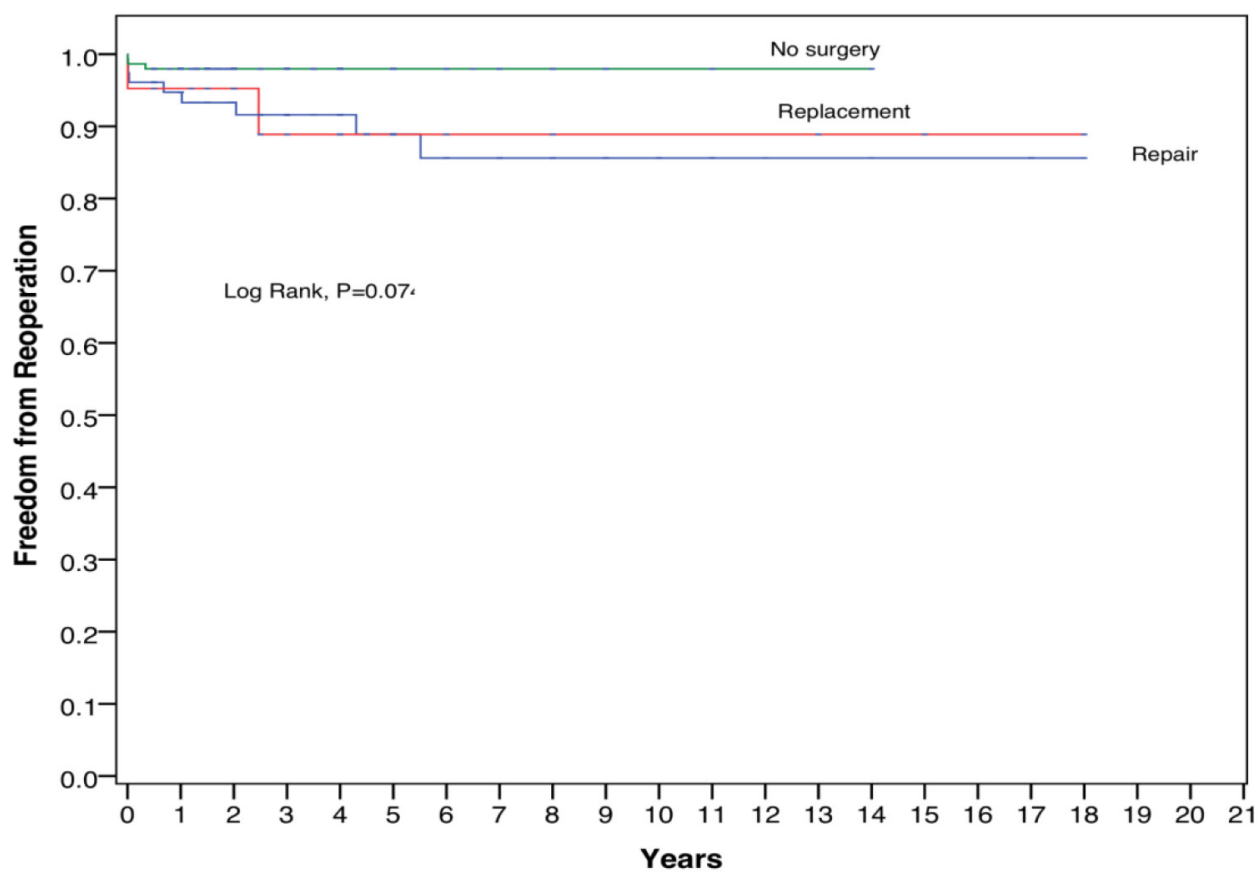

Fig. 3 - Kaplan-Meier curve - freedom from reoperation for various aortic valve interventions. Patient numbers according to the intervention done: no surgery, 156 patients; aortic valve replacement, 21 patients; and aortic valve repair, 84 patients.

timing, and technical details of the surgical procedure ${ }^{[6,7]}$. The ideal management should be one which is safe, simple, reproducible, and durable, and should deal with all the anatomic components of the syndrome, preferably at a young age. In practice, achieving these deceptively simple goals is difficult.

In our series, all patients with a preoperative moderate or severe AR gradient had their aortic valves inspected and assessed during surgery. We had a few criteria which we used to assess the valve on table and this included the effective height of each leaflet, the support from the commissures, symmetrical apposition of the leaflet by using the Nodule of Arientus as a guide, and leaflet appearance. Leaflets which have rolled edges, elongated and asymmetrical, underwent repair even if the AR was only mild. We also had patients with had moderate $A R$, but with normal cusp and commissures, who had NI to their aortic valve. All this assessment was solely decided by the operating surgeon and this is one of the main limitations of our study as we had no standard criteria to select patients for AVr.

In the mild AR group, we had two AVr that failed, both of these using the Trussler's technique, and we had six patients that 


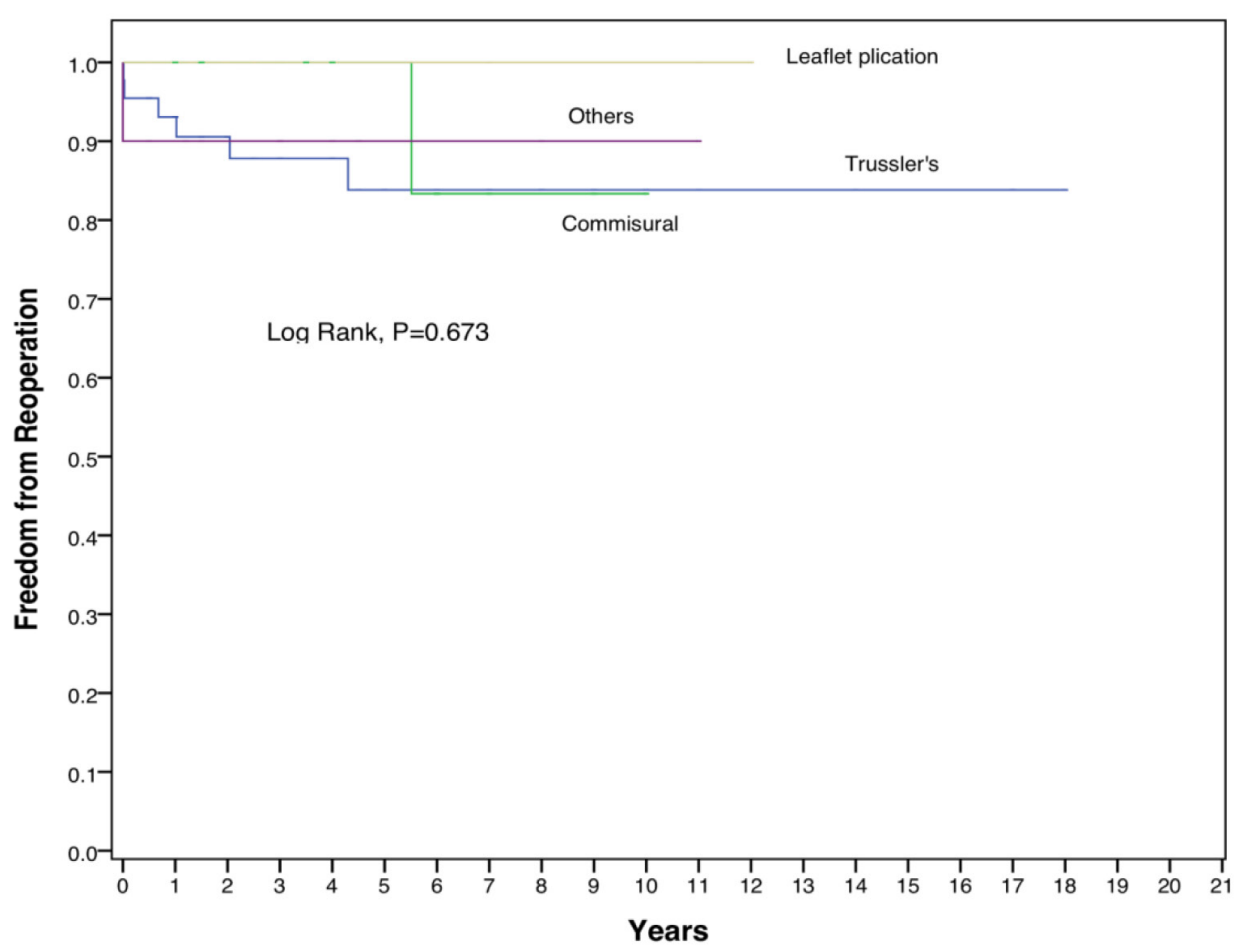

Fig. 4 - Kaplan-Meier curve - freedom from reoperation for various methods of aortic valve repair. Patient numbers based on the type of aortic valve repair: Trussler's repair, 50 patients; commissural-related repair, 13 patients; leaflet plication, 11 patients; others, 10 patients.

had $\mathrm{NI}$ in the mild group progressing to more than moderate AR after the VSD was closed. We feel that the Trussler's repair has its limitations, the patient must be carefully selected, and it is not suitable if there is leaflet elongation. The six patients who had NI to their valve were found to be older children (range: 6 - 8 years old) and all of them had a perimembranous VSD with a size $<1$ $\mathrm{cm}$. The moderate AR group had six patients who had NI, and these patients still had a competent aortic valve on their latest follow-up. We feel that as long the leaflet has no major structural abnormality and it has good commissural support, the closure of the VSD itself should be sufficient. This, however, must be an accurate assessment by the operating surgeon.

Previous studies ${ }^{[2,11]}$ have shown associations between preoperative AR grade and subsequent AR progression as well as the type of intervention. In this study, we further clarify that such association was present between the preoperative AR grade and the progression of the AR in coming years ( $P$-value of $<0.001)$. In addition to the preoperative AR grade, older age at VSD repair $(P<0.001)$ as well as VSD size $(P<0.001)$ also predicted the type of aortic valve intervention. We had 15 patients with mild AR that underwent $A V r$ and this was mainly due to the presence of right coronary cusp prolapse in the doubly committed subarterial group of patients. Although the AR was mild, we decided to plicate the leaflet as it was elongated into the VSD defect as a windsock deformity.

In our study, the median age for AVR was 25 years and none of our patients who needed AVR was younger than nine years old. If the VSD shunt persisted and patients grew older, prolapse would get worse with time and even progressed to sinus of Valsalva aneurysm. The more the damage to the aortic valve, the more likely AVR will be needed ${ }^{[3]}$. This may be the reason why older age at VSD repair predicts the necessity for AVR.

Moreover, it has also been reported that the longer the wait for surgery, the more morphological changes happen to the aortic cusps, making AVr less suitable ${ }^{[8]}$.

AR in patients with VSD is commonly associated with prolapse of the aortic valve cusps, with elongation of the free edge ${ }^{[9]}$. Therefore, attempts to surgically treat AR are directed towards AVr.

In this study, the number of prolapsed aortic cusps were significantly associated with the preoperative grade of $A R$ $(P=0.001)$, and therefore, it had a significant association with the type of aortic valve intervention $(P<0.001)$. Besides that, there was also significant association between the type of $\mathrm{AV} r$ performed with the number of prolapsed cusps in our study $(P=0.002)$.

Indications for $\mathrm{AV} r$ have not been explicitly defined in previous studies. Furthermore, previous reports on the long-term outcome of VSD repair with concomitant $A V r$ were based on a relatively small number of patients.

Among the 84 patients who had $\mathrm{AVr}$ done, most of them underwent Trussler's repair (59.5\%). The type of $\mathrm{AVr}$ employed was significantly associated with the number of prolapsed cusps $(P<0.001)$. Those with three cusps prolapsed mainly had an AVR done (71.4\%). Replacement of an entire aortic valve is not done when only one cusp is prolapsed ${ }^{[10]}$.

Therefore, in those patients with none or one prolapsed cusp, AVr was performed instead of AVR. 
Overall, our 10- and 15-year freedom from reoperation for $A V r$ were $88.9 \%$ and $82.6 \%$, respectively. This compares favorably with other published series which estimates range from $85 \%$ at 10 years to $64 \%$ at 15 years ${ }^{[5,11]}$.

It is important to identify the possible risk factors that are associated with failure of AVr so that better patient selection can be practiced, hoping for better outcome in the future. In this way, the freedom from reoperation for AVr will be acceptable, hence reducing the necessity for AVR.

The advantages (growth potential, avoidance of anticoagulation, and minimal thromboembolic risk) and disadvantages of $A V r$ (residual lesions and need for later valve surgery) must be balanced against the outcomes of AVR so that AVr becomes an attractive and justifiable alternative ${ }^{[4]}$.

It was also noted in this study that the VSD size as well as the postoperative AR grade significantly affected reoperation ( $P$-value of 0.048 and $<0.001$, respectively).

There was no hospital mortality noted in this study period consistent with most other published studies ${ }^{[5,12]}$.

This was a retrospective study through a long period. Indications for surgical intervention on the aortic valve have changed, as have AVR options, techniques of repair, and available material. We did not have a large enough group of patients for $A V r$ as well as AVR, which may have affected our outcome. Although we could not identify a significant difference in freedom from reoperation between $A V r$ and $A V R$, the curves do diverge. It is quite possible that if we had had more patients, this divergence would have reached significance.

$A V r$ is an effective and durable technique for the surgical treatment of AR in patients with VSD. In this study, AVr achieved a satisfactory success rate.

This stressed the importance of early detection and intervention prior to progression of AR, thus reducing the rate of AVR. However, longer follow-up with larger number of patients would provide a better assessment of the outcome of $A V r$ in patients with syndrome of VSD and AR.

Over the years it has always been a debate to decide on when is it safe to intervene this group of patients. A recent publication ${ }^{[13]}$ highlighted that the youngest patient they operated on was at three months old, and this was also the same in our series. In that series, they also found that patients did better when they were operated at a younger age. A similar finding that we also found in our series. We, however, had a longer follow-up and patient cohort to support this finding in comparison with the recent study ${ }^{[13]}$.

The risk of cardiopulmonary bypass has always been the concern for young infants. There have been recent reports on transcatheter closure of VSD in aortic valve prolapse and $A R^{[14]}$. The procedure has been shown to be safe and feasible in the setting of AR. In a recent review for the safety of device closure for VSD, it was found that percutaneous and perventricular device closure for VSD are safe and did not have any extra morbidity ${ }^{[15]}$.

The avoidance of cardiopulmonary bypass will further bring down the operative age and further protect the structural damage to the aortic valve. This will enable early VSD closure and probably $\mathrm{NI}$ for the aortic valve in coming years.

\section{Limitations}

This is a retrospective study and most of the data were collected from the operative notes and patients' medical records. The decision to intervene the valve was solely of the operating surgeon and there was no strict criteria or guideline that was used as a guide for the valve intervention. The actual size of the VSD was also a size that was estimated by the operating surgeon.

\section{CONCLUSION}

We can conclude from our study that all moderate and severe AR with small VSD in older patients with more than one cusp prolapse will need intervention to their aortic valve during the closure of the VSD.

\section{ACKNOWLEDGEMENT}

We would like to thank the operating room staff and the statisticians at IJN, Kuala Lumpur.

\section{No financial support. \\ No conflict of interest.}

\section{Authors' roles \& responsibilities}

SK

Substantial contributions to the conception or design of the work; or the acquisition, analysis, or interpretation of data for the work; drafting the work or revising it critically for important intellectual content; agreement to be accountable for all aspects of the work in ensuring that questions related to the accuracy or integrity of any part of the work are appropriately investigated and resolved; final approval of the version to be published

SS Substantial contributions to the conception or design of the work; or the acquisition, analysis, or interpretation of data for the work; drafting the work or revising it critically for important intellectual content; final approval of the version to be published

JD Substantial contributions to the conception or design of the work; or the acquisition, analysis, or interpretation of data for the work; drafting the work or revising it critically for important intellectual content; final approval of the version to be published

RARM Agreement to be accountable for all aspects of the work in ensuring that questions related to the accuracy or integrity of any part of the work are appropriately investigated and resolved; final approval of the version to be published

AY Agreement to be accountable for all aspects of the work in ensuring that questions related to the accuracy or integrity of any part of the work are appropriately investigated and resolved; final approval of the version to be published

RS Agreement to be accountable for all aspects of the work in ensuring that questions related to the accuracy or integrity of any part of the work are appropriately investigated and resolved; final approval of the version to be published 


\section{REFERENCES}

1. Laubry C, Pezzi C. Traite des maladies congenitales du Coeur. Paris: JN Bailliere: 1921. Quoted by Labury C, Routier D, Soulie P. Les souffles de la maladie de Roger. Rev Med Paris. 1933;50:439-48.

2. Tweddell JS, Pelech AN, Frommelt PC. Ventricular septal defect and aortic valve regurgitation: pathophysiology and indications for surgery. Semin Thorac Cardiovasc Surg Pediatr Card Surg Annu. 2006:147-52. doi:10.1053/j.pcsu.2006.02.020.

3. Chiu SN, Wang JK, Lin MT, Chen CA, Chen HC, Chang Cl, et al. Progression of aortic regurgitation after surgical repair of outlet-type ventricular septal defects. Am Heart J. 2007;153(2):336-42. doi:10.1016/j. ahj.2006.10.025.

4. Tweddell JS, Pelech AN, Jaquiss RD, Frommelt PC, Mussatto KA, Hoffman GM, et al. Aortic valve repair. Semin Thorac Cardiovasc Surg Pediatr Card Surg Annu. 2005:112-21. doi:10.1053/j.pcsu.2005.01.013.

5. Elgamal MA, Hakimi M, Lyons JM, Walters HL 3rd. Risk factors for failure of aortic valvuloplasty in aortic insufficiency with ventricular septal defect. Ann Thorac Surg. 1999;68(4):1350-5. doi:10.1016/s00034975(99)00970-4.

6. Ugan Atik S, Guler Eroglu A. Aortic valve prolapse and aortic regurgitation during long-term follow up in children with ventricular septal defect. J Heart Valve Dis. 2017;26(6):616-23.

7. Yacoub MH, Khan H, Stavri G, Shinebourne E, Radley-Smith R. Anatomic correction of the syndrome of prolapsing right coronary aortic cusp, dilatation of the sinus of valsalva, and ventricular septal defect. JThorac Cardiovasc Surg. 1997;113(2):253-60; discussion 261. doi:10.1016/ S0022-5223(97)70321-0.

8. Komai H, Naito Y, Fujiwara K, Noguchi Y, Nishimura Y, Uemura S. Surgical strategy for doubly committed subarterial ventricular septal defect with aortic cusp prolapse. Ann Thorac Surg. 1997;64(4):1146-9. doi:10.1016/ s0003-4975(97)00718-2.

9. Cheung YF, Chiu CS, Yung TC, Chau AK. Impact of preoperative aortic cusp prolapse on long-term outcome after surgical closure of subarterial ventricular septal defect. Ann Thorac Surg. 2002;73(2):622-7. doi:10.1016/ s0003-4975(01)03393-8.

10. Mariani MA, WaterbolkTW, Strengers JL, Ebels T. Aortic valvuloplasty for aortic insufficiency associated with ventricular septal defect. J Thorac Cardiovasc Surg. 1997;114(5):851-3.

11. Tweddell JS, Pelech AN, Frommelt PC, Jaquiss RD, Hoffman GM, Mussatto $K A$, et al. Complex aortic valve repair as a durable and effective alternative to valve replacement in children with aortic valve disease. J Thorac Cardiovasc Surg. 2005;129(3):551-8. doi:10.1016/j.jtcvs.2004.09.033.

12. Sim EK, Grignani RT, Wong ML, Quek SC, Wong JC, Yip WC, et al. Outcome of surgical closure of doubly committed subarterial ventricular septal defect. Ann Thorac Surg. 1999;67(3):736-8. doi:10.1016/s00034975(98)01256-9.

13. Jung $\mathrm{H}$, Cho $J Y$, Lee Y. Progression of aortic regurgitation after subarterial ventricular septal defect repair: optimal timing of the operation. Pediatr Cardiol. 2019;40(8):1696-702. doi:10.1007/s00246-019-02206-z.

14. Ghosh S, Sridhar A, Solomon N, Sivaprakasham M. Transcatheter closure of ventricular septal defect in aortic valve prolapse and aortic regurgitation. Indian Heart J. 2018;70(4):528-32. doi:10.1016/j. ihj.2017.11.023.

15. Huang XS, Luo ZR, Chen Q, Yu LS, Cao H, Chen LW, et al. A comparative study of perventricular and percutaneous device closure treatments for isolated ventricular septal defect: a Chinese single-institution experience. Braz J Cardiovasc Surg. 2019;34(3):344-51. doi:10.21470/1678-97412018-0351. 